\title{
Informação e cidadania, a nova configuração da democracia*
}

\author{
Joãomar Carvalho de Brito Neto*
}

\section{Resumo}

Este trabalho sintetiza os resultados de uma pesquisa de campo realizada em uma comunidade afro-brasileira do norte de Goiás - os kalunga. $\mathrm{O}$ autor aborda a estrutura e o funcionamento da comunidade local em sua relação com o sistema brasileiro de informação e comunicação, analisando os processos que envolvem informação e cidadania.

Palavras-chave: informação e cidadania, democracia da informação.

\section{Introdução}

A informação está no centro de uma concepção contemporânea de cidadania. Por isso, ela não pode se resumir à sua dimensão midiática, pois ela é conhecimento humano, elemento indispensável à constituição do ser político, do cidadão, segundo sustenta o pedagogo Paulo Freire, para quem "o homem é um ser da práxis, da ação e da reflexão" 1 .

Segundo ele, "o homem, como ser de relações, desafiado pela natureza, a transforma com seu trabalho; e o resultado desta transformação, que se separa do homem, constitui seu mundo. O

* Texto apresentado no V Simpósio de Pesquisa em Comunicação do Centro-Oeste, realizado em Goiânia - Go, entre 20 a 22/05/99.

** Professor da Faculdade de Comunicação e Biblioteconomia da Universidade Federal de Goiás e Doutorando na Universidade de Paris 8.

Comun. Inf., v. 2, n. 2, p. 229-242, jul./dez. 1999 


\section{0}

mundo de cultura que se prolonga no mundo da história... A intersubjetividade ou a intercomunicação é a característica primordial deste mundo cultural e histórico" 2 . Desse modo, segundo Freire, o mundo do homem não existiria se ele não fosse capaz de comunicar.

Venício Artur de Lima revela, por sua vez, que, "enfatizando que a comunicação significa co-participação dos sujeitos no ato de pensar, que o objeto de conhecimento não pode se constituir no termo exclusivo do pensamento mas, de fato, é seu mediador, e que o conhecimento é constituído através das relações entre os seres humanos e o mundo, Freire está, na verdade, definindo a comunicação como a situação social em que as pessoas criam conhecimento juntas, ao invés de transmiti-lo, dá-lo ou impô-lo. A comunicação é uma interação entre sujeitos iguais e criativos. Mas esta interação é de natureza tal que necessita estar fundada no diálogo"3.

Assim, a informação abarcaria uma lógica educadora, na medida em que ela forma a consciência política e melhor agenda o indivíduo para o convívio social e para o exercício da cidadania. Esta circunstância é que, essencialmente, define o processo democrático.

Mas a informação tem sua lógica mercantil, sobretudo dentro desta sua dimensão midiática, na medida que se tornou um produto a ser comercializado. Mais grave e revelador do que isso é, no entanto, sua lógica política, como bem assinala Rubim, para quem "a essência da comunicação midiática - nomeada habitualmente com as problemáticas expressões 'social', 'coletiva' ou 'de massas'- passou a ser algo mais: a constituição da dimensão pública da sociedade contemporânea".

Segundo o autor, "a comunicação midiática se pretende a única possuidora do dom de publicizar e, mais do que isso, ela tenciona se identificar, sem mais, com a própria dimensão pública da sociedade, reduzindo-a a seus limites e ditames". Outra sua característica é a configuração da sua dimensão pública. Ela aparece como específico espaço social, habitado e vivenciado "por imagens".

Comun. Inf., v. 2, n. 2, p. 229-242, jul./ dez. 1999 
Segundo Rubim, "a constituição de uma dimensão pública, na qual só é possível transitar sob a forma de 'imagens', tem um enorme impacto e repercute fortemente sobre a atividade política: impõe a dimensão pública como lugar de luta de todos os embates políticos (a construção social de "imagens" é um componente da atividade política); isto sugere o desenvolvimento de ações políticas específicas e essenciais no campo da comunicação e a comunicação midiática tem a capacidade de agendar os temas em discussão. Isto significa que "o processo de construção da realidade, através dos meios de produção e difusão de bens simbólicos, não se realiza apenas pela remissão a um acontecido. $\mathrm{A}$ constituição da realidade exige o acionamento de regras próprias de produção e de estoques culturais disponíveis na sociedade (constituição do imaginário) ${ }^{4}$.

Dentro desta linha é que fomos encontrar os camponeses negros da chamada comunidade kalunga, norte de Goiás, vivendo uma experiência política de uso da informação, que lhe foi permitindo enxergar, descobrir e trabalhar uma perspectiva de direitos, historicamente escondidos e negados sob o manto do processo de exclusão social a que estão submetidas camadas consideráveis de pequenos e médios lavradores brasileiros ${ }^{5}$.

Primeiro, descobriram que as terras em que viviam há muitos anos, estavam sendo griladas. E começaram a denunciar. Depois, começaram a sofrer ameaças e violências. Com ajuda de simpatizantes, puderam ganhar visibilidade social e frear o processo. Em meados dos anos 80 , a construção de uma usina hidrelétrica, que alagaria grande parte de suas terras, desencadeou um processo político, com duas dimensões: internamente, aquelas familias começaram a se organizar e a se articular com simpatizantes de sua causa fora de seus limites territoriais; externamente, o ambiente político, em clima de Assembléia Constituinte, logrou uma boa interação entre as duas perspectivas. Isso lhes permitiu ganhos materiais - regularização de parte de suas terras e, principalmente, o desabrochar de uma consciência de cidadania, apoiada num amadurecido e cada vez mais consistente processo de reivindicações.

Comun. Inf., v. 2, n. 2, p. 229-242, jul./ dez. 1999 


\section{Informacão e cidadania}

A cidadania está no centro de uma concepção democrática contemporânea e, por isso, encontra-se obrigatoriamente presente no discurso político de todo mundo. O processo de globalização em curso, em razão da onda generalizada de exclusão dele decorrente, recolocou o debate sobre a questão democrática e as implicações inevitáveis sobre o universo dos direitos fundadores da cidadania, no sentido estabelecido por T. H. Marshall ${ }^{6}$.

O que parece evidente é que a democracia está em jogo ultimamente, porque tem-se a impressão de que há uma clara possibilidade de aniquilamento de conquistas históricas, que foram responsáveis pela emergência da cidadania como a grande dimensão política do homem. Ou como assinala Tourraine, "numa sociedade pós-industrial, em que as indústrias culturais - educação, saúde e assistência social, informação - desempenham um papel mais central do que a proteção dos bens materiais, o destino da democracia está em jogo por toda parte, seja no hospital, no colégio ou na universidade, no jornal ou na rede de tv ou nas empresas de produção"7.

Apesar desse quadro pouco animador, o Brasil experimentou um sentimento diferente em relação à construção da cidadania eternamente prometida, mas historicamente negada. O sociólogo Herbert de Souza, o Betinho, que coordenou o movimento Ação da Cidadania contra a Miséria e pela Vida, garantiu que "a democracia vem aí e vem pelas mãos da cidadania, esta onda tão forte que é capaz de andar na contramão e se encontrar com a história"8), referindo-se ao crescimento dos movimentos sociais, responsáveis por significativos avanços e transformações no cenário da vida brasileira

É dentro dessa linha que o filósofo belga André Berten lembra que "devemos refletir sobre os modelos de democracia, a partir de uma reconstrução das competências individuais. Isto quer dizer que só é possível pensar uma democracia quando constituída por indivíduos adultos e racionais"(..), se inspirando cer-

Comun. Inf., v. 2, n. 2, p. 229-242, jul./dez. 1999 
tamente nas intuições de Piaget, Kolberg e Habermas sobre as intrínsecas ligações entre competências cognitivas e competências morais (9).

Isso indica que a informação está mesmo no centro de uma nova concepção contemporânea da cidadania. Isso se verifica tanto em nível do conteúdo veiculado pelos meios de comunicação, quanto em nível do que a pessoa recebe do sistema dos repertórios tradicionais de produção, manutenção e transformação de informação/conhecimento (família, religião, escola e mídia). Segundo Blandine Kriegel, “( ...) nenhuma sociedade começa a existir por um contrato voluntarista celebrado entre os indivíduos. Ela começa pela história e se perpetua pela transmissão. O contrato, isto é, o momento da perpetuação, só vem mesmo em segundo lugar, quando se permite a cada geração decidir o que é verdadeiramente útil à vida coletiva"10.

Cidadania é um conceito em construção. É produto da história. O estudo dos movimentos sociais e políticos revela que os direitos humanos são uma construção permanente e dificil. Como constata Freire Costa, "o modo de vida democrático é absolutamente minoritário na história das culturas. A democracia não é é produto da evolução do homem e da razão. É produto da história"11.

O que vem a ser, pois, cidadania? Wanderley Guilherme dos Santos sugere que "o conceito-chave que permite entender a política econômico-social pós-30, assim como fazer a passagem da esfera da acumulação para a esfera da eqüidade é o conceito de cidadania, implícito na prática política do governo revolucionário, e tal conceito poderia ser descrito como de cidadania regulada. Por cidadania regulada, entendo o conceito de cidadania, cujas raízes encontram-se, não em um código de valores políticos, mas em um sistema de estratificação ocupacional, e que, ademais, tal sistema de estratificação é definido por norma legal. Em outras palavras, são cidadãos todos aqueles membros da comunidade que se encontram localizados em qualquer uma das ocupações reconhecidas e definidas em lei. A extensão da cidadania se faz, pois, via regulamentação de novas profissões e/ou ocupa-

Comun. Inf., v. 2, n. 2, p. 229-242, jul./dez. 1999 


\section{4}

ções, em primeiro lugar, e mediante ampliação do escopo dos direitos associados a estas profissões, antes que por expansão dos valores inerentes ao conceito de membro da comunidade"12.

\section{Kalunga e exclusão}

Os camponeses negros kalunga vivem numa área de $237 \mathrm{mil}$ hectares nos municípios de Cavalcante, Monte Alegre e Teresina de Goiás, às margens do rio Paranã. Exploram a agricultura e a pecuária. Aventou-se a possibilidade de que fossem remanescentes de um quilombo que, desde o século XVIII, teria resistido a tudo e a todos e permanecido incólume até os dias de hoje. Não há, contudo, evidências históricas ou lógicas que possam comprovar esta possibilidade.

Sabe-se que a importância de um quilombo se mede tanto pela preocupação social e pelo desconforto político que provocou nas autoridades da época, quanto pelos vestígios que deixou. Não parece ter sido o caso presente, tanto pela verificação da correspondência oficial, quanto pela ausência de sinais de sua constituição material naquela área. A propósito, uma das poucas pistas de existência de quilombos na região enconra-se no relatório do governador Dom João Manoel de Melo: ele revela que, por volta de 1760, existiam alguns quilombos na região do rio Paranã, chegando a reunir cerca de 200 escravos fugitivos. As autoridades tiveram que contê-los, mas não há registros de sua organização social, política, econômica ou de sua organização militar. A partir daquela data, a história não mais registra a existência de quilombos em Goiás, embora a escravidão só viesse a ser abolida mais de um século depois, em $1888^{13}$.

Naquela época, já estava em curso o processo de decadência da mineração na Província de Goiás, fragilizando sua economia. Isto porque, "em Goiás, deixou-se de importar escravos a partir de 1775 , pois a decadência em produção e produtividade das minas fazia com que os mineiros tivessem perdido todo o crédito junto às companhias importadoras de escravos"14. Desde então, a região teve nova realidade econômica, assentada na pecuá-

Comun. Inf., v. 2, n. 2, p. 229-242, jul./ dez. 1999 
ria extensiva e na agricultura de subsistência. Parece lógico supor que, eliminadas as razões que provocaram e explicaram seu aparecimento, os quilombos tenham deixado de vez o panorama social da província interiorana.

Celso Furtado afirma que "não se havendo criado nas regiões mineiras formas permanentes de atividades econômicas - à exceção de alguma agricultura de subsistência - era natural que, com o declínio da produção de ouro, viesse uma rápida e geral decadência". Com isso, acrescenta o autor, "muitos dos antigos empresários transformaram-se em simples faiscadores e com o tempo revertiam à simples economia de subsistência. Uns poucos decênios foi o suficiente para que se desarticulasse toda a economia da mineração, decaindo os núcleos urbanos e dispersando-se grande parte de seus elementos numa economia de subsistência, espalhados por uma vasta região em que eram difíceis as comunicações e isolandose os pequenos grupos uns dos outros"15.

Assim, os kalunga teriam se originado de semelhante processo. Outros grupos do interior do Brasil apresentam características sócio-culturais semelhantes, todas centradas na estrutura familiar e no isolamento físico. A dispersão generalizada, numa região periférica da sociedade brasileira, permitiu a esses grupos a manutenção de determinadas características sócio-ambientais, com base em pequenas estruturas familiares, embora não tenham podido assegurar a continuidade de determinadas práticas culturais, a não ser algumas manifestações religiosas ou festivas, já com sinais evidentes da influência da Igreja Católica.

Os kalunga, ao preservarem essas características (que não são exclusivas), num ambiente culturalmente acanhado, conseguiram manter a unidade do grupo, preservando valores de uma cidadania informal, "solidificada no estatuto em que o homem + terra + natureza é o somatório e cujo ambiente geográfico é o agrário. É dentro desse compartimento do agrarismo, como divisão de terras com agricultores, que os chamados kalunga vivem, moram e têm culturas diferenciadas dos demais cidadãos que habitam a região"16.

Comun. Inf., v. 2, n. 2, p. 229-242, jul./ dez. 1999 


\section{6}

$\mathrm{Na}$ realidade, a maior parte da população dessa região é negra, mas sua constituição é diferenciada. Muitos descendem, em escala longínqua, dos antigos escravos que foram trazidos para a região no século XVIII. Muitos outros chegaram posteriormente, principalmente no bojo da Marcha para o Oeste, a partir dos anos 30. Outros chegaram à região nos anos 50 , vindos de outros estados, atraídos pela valorização daquela área.

\section{Consciência de direitos}

Até a redescoberta econômica (riquezas minerais, sobretudo) da região norte de Goiás (antigo nordeste goiano) pelos governos militares, moradores como os kalunga viviam em terras cuja titularidade não tinha amparo legal. A partir daí, os governos militares determinaram novas legislações sobre o uso e a ocupação da terra. Assim, não ter títulos de posse da terra significava a possibilidade de perdê-la, mesmo nela vivendo há dezenas de anos. Muitos perderam suas terras e mudaram-se para os centros urbanos. Outros ficaram à mercê da ação violenta dos grileiros ou de proprietários de terras.

Uma denúncia de grilagem precipitou, no entanto, uma reação ainda que tímida desses moradores e se iniciou um processo de visibilidade social para aqueles moradores. Isto gerou, a partir de 1984, uma resposta positiva do governo de Goiás, que conseguiu regularizar parte daquelas terras, no município de Monte Alegre. As demais áreas (em Cavalcante e Teresina) ainda aguardam solução.

A antropóloga Mari de Nasaré Baiocchi, que estuda esse grupo desde o início dos anos 80 , sempre garantiu tê-los "descoberto" ("dizem sermos nós - o grupo de pesquisa - os primeiros estranhos a chegar até lá") ${ }^{18}$, embora seu propalado isolamento nunca tenha sido total ou excepcional. No entanto, seus esforços em favor desses moradores, principalmente levantando a questão fundiária, resultou na criação do Sítio Histórico e Patrimônio Cultural Kalunga, em 1991.

Comun. Inf., v. 2, n. 2, p. 229-242, jul./dez. 1999 
Desde os anos 50, esses moradores, produtores de farinha de mandioca e de rapadura, são conhecidos nas cidades vizinhas. $\mathrm{E}$ no início dos anos 60, agentes da Sucam-Superintendência de Erradicação da Malária já desenvolviam trabalhos junto aos "negros do vale do Paranã", conforme atesta Avelino Rodrigues Carvalho, o pioneiro nesse trabalho. Isto, evidentemente, desautoriza cabalmente a "teoria da descoberta dos kalunga" feita pela antropóloga Baiocchi, responsável por nominá-los de "kalunga", termo ainda pouco assimilado por grande parte deles que, em passado recente, tinham nesta nominação uma provocacão dos moradores dos pequenos centros urbanos vizinhos.

A tentativa do governo federal de construir, em 1988, uma usina hidrelétrica na área em que vivem os kalunga colocou-os na mídia nacional, despertou solidariedade até internacional, como se fossem um grupo de seres especialmente diferentes. Não são, como já vimos. No entanto, essa visibilidade permitiu que se organizassem e lutassem por suas terras, pois se descobriu, posteriormente, que grande parte delas eram terras devolutas (pertencentes ao Estado) e que poderiam, claramente, lhes pertencer mediante uma ação concreta do governo do Estado. É esse processo que ainda está em curso.

\section{Conclusão}

A barragem da hidrelétrica não foi construída. O projeto ainda está de pé, porque o governo federal considera a região importante para garantir, num futuro, o abastecimento de energia para a região Centro-Oeste. Mas aqueles moradores hoje são outras pessoas. Aprenderam a reivindicar, como os dos centros urbanos. Continuam brigando pela regularização das terras ainda não beneficiadas pela ação do governo. Reivindicaram escolas. Vários grupos deles já foram beneficiados com escolas.

Hoje agentes de saúde, recrutados entre eles, percorrem os cerca de 700 grupos familires da região, prestando assistência. $\mathrm{O}$ fato de terem sido considerados remanescentes de quilombos os

Comun. Inf., v. 2, n. 2, p. 229-242, jul./ dez. 1999 


\section{8}

ajudou muito, mas o grosso de seus problemas ainda continua de pé: a questão da terra demanda esforços políticos e recursos que o Estado sempre alega não dispor para resolver, de vez, esse problema antigo.

Grupos com as características dos kalunga existem às dezenas no interior de Goiás. Residentes fixos, frutos da dispersão populacional iniciada com o fim da mineração no século XVIII, os kalunga constituem uma experiência interessante do ponto de vista de recuperação da idéia da cidadania e do exercício dos direitos humanos fundamentais.

É preciso que se diga, no entanto, que grande parte de suas conquistas (escola e saúde) se deve, principalmente, a fatores exógenos: foram as pressòes externas que lhes garantiram o que têm hoje em dia. Sua capacidade de resistência ou de pressão junto ao Estado nunca poderia ter sido maior, se considerarmos que grande parte deles é ainda analfabeta. Ou seja, a questão da cidadania ainda está em aberto, até porque, em épocas eleitorais, são muito usados como massa de manobra ou para promessas eleitoreiras.

No entanto, já se pode dizer que, entre eles, existe uma consciência de direitos: sabem o que querem, embora não se iludam quanto ao fato de suspeitarem que pertencem ao grande universo de excluídos deste país. Como bem salienta o escritor Emílio Vieira, filho da região, "o grande problema desses moradores não é quilombo, mas quilômetro", referindo-se ao isolamento típico dessas formações sociais, só bafejadas pelo progresso quando têm que ser retiradas do seu lugar de vida, para não prejudicar a célere caminhada do progresso.

Sem informação/conhecimento, o homem não consegue dar o passo de qualidade no ambiente social. Ele não se transforma em militante de sua própria história, da qual é, a um só tempo, autor $\mathrm{e}$ ator. Vale dizer, sem a informação $\mathrm{o}$ indivíduo nào se torna cidadão, pois o exercício da cidadania só se dá quando o homem se dá conta do que é e do que poderá ser. Os pré-requisitos da cidadania (educação, saúde, segurança, transporte, moradia e trabalho) só podem ser atendidos quanto for possível a cada

Comun. Inf., v. 2, n. 2, p. 229-242, jul./ dez. 1999 
pessoa o acesso à informação/conhecimento sobre os outros (sociedade), sobre a experiência humana (história) e sobre a sua própria experiência de construção do seu projeto de vida (utopia).

O sociólogo Herbert de Souza, Betinho, conseguiu que a sociedade brasileira visse na cidadania, não somente um estatuto de direitos e deveres, mas um personagem que sempre esteve ausente da vida do brasileiro, embora absolutamente imprescindível ao projeto democrático. O Brasil começou a superar e a vencer, com as campanhas de Betinho, o receio e o pavor de o povo encontrar-se com este personagem, cujo rosto foi esculpido pela elite, em forma de exclusão.

Com os kalunga ocorreu idêntico processo como, de resto, o encontro continua se dando em todos os recantos do país. Primeiro, eles se descobriram negros, pobres e abandonados. Depois, lhes disseram que isso era bom, na medida em que significava a possibilidade de recebimento de atenções especiais e específicas. Descobriram que tudo isso era bobagem. Preto e pobre tomaram consciência dessa realidade - não era "privilégio" deles. Começaram a olhar em volta e estão percebendo um Brasil feito de negros e pobres. Mas estão começando a entender que tudo isso pode mudar, a partir deles. Eles se descobriram brasileiros.

Eles se descobriram excluídos da sociedade brasileira: não tinham documentos de identidade (não eram gente), não tinham terra (e quem tinha estava ameaçado de perdê-la), não tinham o respeito dos seus vizinhos... E, muito pior, eram chamados de "kalunga", um termo pejorativo na região: descobriram que eram considerados preguiçosos, criadores de caso, sem importância alguma. Afastados fisicamente das cidades a maior parte do seu tempo, ainda tinham contra si histórias fantasiosas a seu respeito, que em nada ajudavam a compreender sua condição de brasileiros excluídos da comunidade nacional.

No entanto, descobriam que, tendo documentos pessoais, indo à escola, pedindo e recebendo assistência médica e que, lutando $\mathrm{e}$ buscando parcerias, poderiam até mesmo conquistar a terra onde viviam, que poderiam mudar todo o jogo a seu favor. Podiam,

Comun. Inf., v. 2, n. 2, p. 229-242, jul./ dez. 1999 
enfim, fazer aquele tão esperado encontro com aquele personagem distante, pelo o não-saber e a não-informação, batizado pelo pregador Betinho, pelo nome de cidadania.

\section{Abstract}

This work synthesizes the results of a field research accomplished in an Afro-Brazilian community of the north of Goiás - the kalunga. The author approaches the structure and the local community's operation in its relationship with the Brazilian system of information and communication, analyzing the processes that involve information and citizenship.

Key words: information and citizenship; systen of information and commucation; Afro-Brazilian community.

\section{Notas}

1. FREIRE, Paulo. Comunicafão ou Extensão? 2.ed. Rio de Janeiro: Paz e Terra. 1985. p. 28.

2. Ibid. p. 65.

3. ARTUR DE LIMA, Venício. Comunicafão e cultura: as idéias de Paulo Freire. Rio de Janeiro: Paz e Terra; 1981. pp. 64-65.

4. RUBIM, Antônio Albino Canelas. Democratizaçào, comunicação e política: desafio contemporâneo. INTERCOM - Revista Brasileira de Comuniucafão, Sào Paulo, v. 15, n. 1. p. 120-127, jan./jun.1992.

5. CARVALHO DE BRITO NETO, Joãomar. Serra goiana tem quilombo de 150 anos. Jornal do Brasil, Rio de Janeiro, 23 ago. 1987.

6. MARSHALL, Thomas Humpfrey. Class, citizenship, and social development. New York: Doubleday, 1964. Chapter IV. Ciizenship and Social Class. p. 65-122 1994.

7. TOURRAINE, Alain. Qu'est-ce que la démocratie? Paris: Fayard,

8. SOUZA, Herbert de. São Paulo. Folha de S.Paulo, 25 fev. 1994. p. 3.

9. BERTEN, André. Démocratie, convention et inférence: ethique et droit à l'âge démocratique. Les Cahiers de Philosophie Politique et Juridique, Centre de Publication de l'Université de Caen, n. 18, p. 127, 1990.

10. KRIEGEL, Blandine. La crise de la citoyenneté. In: HERZOG, Philippe et alii. Quelle démocratie, quelle citoyenneté. Paris: Les Éditions de l'Atelier/Éd. Ouvrières, 1995. p. 50.

Comun. Inf., v. 2, n. 2, p. 229-242, jul./ dez. 1999 
11. FREIRE COSTA, Jurandir. São Paulo. Isto-É, n. 1202, 14 nov. 1992. (Entrevista).

12. SANTOS, Wanderley Guilherme dos. Cidadania e justifa: a política social na ordem brasileira. 2.ed. Rio de Janeiro: Campus, 1987. p. 68.

13. SALLES, Gilka Vasconcelos Ferreira de. Economia e escravidão na Capitania de Goiás. Goiânia: Cegraf-UFG, 1992. p. 289.

14. PALACIN, Luis, MORAES, Maria Augusta Sant'Anna de. História de Goiás. 6.ed. Goiânia: Ed. UCG, 1994. p. 31.

15. FURTADO, Celso. Formaģão econômica do Brasil. 24.ed. São Paulo: Nacional, 1991. p. $75,84,85$.

16. SOARES, Aldo Asevedo. Kalunga: o direito de existir (questões antropológicas e jurídicas sobre remanescentes de quilombo). Brasília: Fundação Palmares, 1995

18. BAIOCCHI, Mari de Nasaré. Calunga-Kalunga:universo cultural. Revista do Instituto Histórico e Geográfico de Goiás, Goiânia, v. 11, p. 75, jan.1985.

\section{Referências Bibliográficas}

MARSHALL, T.H. Class, citizenship, and social development. New York. Doubleday. 1964.

TOURRAINE, Alain. Qu'est-ce que la démocratie? Paris: Fayard. 1994.

SOUZA, Herbert de. São Paulo. Folha de São Paulo, 25 fev. 1994.

BERTEN, André. Démocratie, convention et inférence: ethique et droit à l'âge démocratique. Les Cabiers de Philosophie Politique et Juridique, Centre de Publication de l'Université de Caen, n. 18, 1990.

KRIEGEL, Blandine. La crise de la citoyenneté. In: HERZOG, Philippe et alii. Quelle démocratie, quelle citoyenneté. Paris: Éd. l'Atelier/Éd. Ouvrières, 1995.

FREIRE COSTA, Jurandir. Sào Paulo. Isto-É, 14 out. 1992. (Entrevista).

SANTOS, Wanderley dos. Cidadania e justiça: a política social na ordem brasileira. 2.ed. Rio de Janeiro: Campus, 1987.

CARVALHO DE BRITO NETO, Joãomar. Serra goiana tem quilombo de 150 anos. Jornal do Brasil, Rio de Janeiro, 23 ago. 1987.

SOARES, Aldo Azevedo. Kalunga: o direito de existir (questões antropológicas e jurídicas sobre remanescentes de quilombos. Brasilia: Fundação Palmares, 1995.

SALLES, Gilka Vasconcelos Ferreira. Economia e Escravidão na Capitania de Goiás. Goiânia: Cegraf/UFG, 1992.

Comun. Inf., v. 2, n. 2, p. 229-242, jul./ deq. 1999 
PALACÍN, Luis e MORAES, Maria Augusta Sant'Änna de. História de Goiás. Goiânia: UCG-Ed., 1994.

FURTADO, Celso. Formasãa econômica do Brasil. São Paulo: Nacional, 1991.

BAIOCCHI, Mari de Nasaré. Calunga-Kalunga: universo cultural. Revista do Instituto Histórico e Geográfico de Goiás, Goiânia, v. 11, jan. 1986.

RUBIM, Antônio Albino Canelas. Democratização, comunicação e política: desafio contemporâneo. INTERCOM-Revista Brasileira de Comunicaf̧ão, São Paulo, v. 15, n. 1, p. 120-127, jan./jun. 1992.

LIMA, Artur Venício de. Comunicafão e cultura: as idéias de Paulo Freire. Rio de Janeiro: Paz e Terra, 1981.

FREIRE, Paulo. Comunicação ou Extensào? Rio de Janeiro. Paz e Terra. 1985. 